\title{
Influence of organic amendments on the sorption of pentachlorophenol on soils
}

\author{
LI Ruijuan, WEN Bei*, ZHANG Shuzhen, PEI Zhiguo, SHAN Xiaoquan*
}

State Key Laboratory of Environmental Chemistry and Ecotoxicology, Research Center for Eco-Environmental Sciences, Chinese Academy of Sciences, Beijing 100085, China. E-mail: ruijuan929@163.com

Received 22 April 2008; revised 22 May 2008; accepted 28 May 2008

\begin{abstract}
The influence of $\mathrm{pH}$ on the sorption of pentachlorophenol (PCP) onto three organic amendments, char, humic acid (HA) and peat, and the effect of organic amendments on PCP sorption to three kinds of soils were evaluated. The sorption of PCP on these sorbents fitted the Freundlich model well, suggesting that PCP sorption isotherms were nonlinear with exponential coefficient $(N)$ value lower than 1 . The PCP sorption capacity on three organic amendments and the $N$ values increased with decreasing $\mathrm{pH}$. The sorption capacities were in the order: char > HA > peat. Organic amendments resulted in an enhancement of sorption capacities of soils. The $N$ values of PCP sorption on soils were decreased by char amendment and increased by HA and peat amendments. This study demonstrated that application of traditional organic amendments led to the enhancement of PCP sorption by soils. This information may aid both in predicting environmental fates of hydrophobic ionizable organic compounds and in developing remediation strategies for them.
\end{abstract}

Key words: sorption; pentachlorophenol; char; peat; humic acid; $\mathrm{pH}$

DOI: $10.1016 /$ S1001-0742(08)62294-9

\section{Introduction}

Soil is regarded as the ultimate sink for large number of organic contaminants in terrestrial (Davies et al., 1999; Skrbic and Durisic-Mladenovic, 2007). Various forms of natural organic matter (NOM) associated with soils serve as dominant "compartments" for sorption and sequestration of hydrophobic organic chemicals (HOCs). The sorption and desorption behaviors of HOCs to different NOMs vary markedly. The leaching behaviors and bioavailability of organic pollutants in soil are affected mainly by soil organic matter concentration and composition (Hatzinger and Alexander, 1995; Dercova et al., 2006).

Organic amendment is a common practice in agriculture to improve the physical and chemical properties of soils at low cost. It increases soil organic matter content and offers many benefits, such as improvement of soil aeration, water infiltration, nutrient-holding capacity, and adjustment of soil pH (Mbagwu and Piccolo, 1989). Most of the traditional organic amendments, such as peat, char, and humic acid, are naturally occurred and environmentally friendly. Therefore, organic amendment is regarded as one of the most suitable technologies for the sustainable agriculture.

In addition to the soil property modification, organic amendment also affects the sorption of organic contaminants. The amendment of both natural and engineered natural materials significantly increases the sorption and

\footnotetext{
* Corresponding author. E-mail: bwen@rcees.ac.cn (WEN Bei); xiaoquan@rcees.ac.cn (SHAN Xiaoquan)
}

decreases the extractability and bioavailability of polycyclic aromatic hydrocarbons (PAHs) from contaminated soil (Tang and Weber, 2006; Weber et al., 2006; Tang et al., 2007). Amendment with both humic acid (HA) and peat was reported to increase the adsorption and decrease leaching of ethametsulfuron-methyl in soils ( $\mathrm{Si}$ et al., 2006). However, Hernández-Soriano et al. (2007) found that HA could induce an adsorption increasement of diazinon, dimethoate, malathion, and methidathion, while peat did not affect pesticide adsorption significantly. Char has been proven to be a highly effective sorbent for organic contaminants (Cornelissen et al., 2004; Zhu et al., 2005). Sheng et al. (2005) found that wheat char could adsorb diuron, bromoxynil, and ametryne effectively. Therefore, char could significantly influence the environmental fate of pesticides.

Pentachlorophenol (PCP) and its salt have been worldwidely applied for more than 50 years as a biocide in both industry and agriculture, which led to serious soil contamination. In China, PCP was used extensively from 1960s until 2000 as a major molluskacide to kill Oncomelania hupensis, which is the intermediate host of schistosomes (Ge et al., 2007). Thus, it is interesting to predict the environmental fate of PCP and to develop potential remediation technologies for PCP contaminated soils. The aim of this study is to evaluate the influence of $\mathrm{pH}$ on PCP sorption onto three common organic amendments including char, $\mathrm{HA}$, and peat, and the sorption enhancement of PCP onto three different kinds of soils amended with char, HA or peat. The related mechanisms were also discussed. 


\section{Methods}

\subsection{Chemicals and materials}

Reference standard of PCP was purchased from AccuStandard Inc. (USA) and stored in sealed volumetric flasks $\left(1.0 \mathrm{mg} / \mathrm{mL}\right.$ in methanol and preserved at $\left.4^{\circ} \mathrm{C}\right)$. Methanol (Fisher, USA) was of HPLC grade. Calcium chloride dehydrate (Beijing Chemical Reagents Company, China) were of analytical grade. Sodium azide (Dongyang Tianyu Chemical Ltd., Zhejiang, China) was of chemical grade. Acetic acid (Siuopharm Chemical Reagent Co., Ltd., Zhejiang, China) was of guaranteed grade.

Stock solution of PCP was mixed with background electrolyte $\left(0.01 \mathrm{~mol} / \mathrm{L} \mathrm{CaCl}_{2}\right.$ containing $\left.100 \mathrm{mg} / \mathrm{L} \mathrm{NaN}_{3}\right)$ to make an initial aqueous concentration in the range of $20-8000 \mu \mathrm{g} / \mathrm{L}$ for sorption experiments.

Three cultivated soils were collected from Jiangxi Province, South China (Jiangxi soil); Beijing, North China (Beijing soil); Hebei Province, North China (Hebei soil). The soils were air-dried, ground, and passed through a 60mesh sieve to remove stones, plant roots, and other large particles. Soil $\mathrm{pH}$ was measured in $0.01 \mathrm{~mol} / \mathrm{L} \mathrm{CaCl}_{2}$ solution using a soil/solution ratio of 1:5 $(\mathrm{W} / \mathrm{V})$. Organic matter content was determined by the Walkley-Black procedure (Nelson and Sommers, 1982). The particle size distribution was measured by the Beijing Forest University Soil Testing Laboratory using pipet method (Day, 1965) (Table 1).

Three organic amendments including char, peat, and HA, were used. Char was prepared by atmospheric pyrolysis according to the method by Braida et al. (2003). Willow-wood shavings were placed in a $15-\mathrm{cm}$ watchglass-covered crucible and heated at $400^{\circ} \mathrm{C}$ for $2 \mathrm{~h}$. Peat was commercially available (Klasmann-Deilmann $\mathrm{GmbH}$, Germany). HA was isolated from peat according to the International Humic Substances Society (IHSS) procedure as described in our previous work (Wen et al., 2007). The obtained char, HA, and peat were dried, pulverized gently in a mortar to pass through a $0.25-\mathrm{mm}$ sieve, and stored in a glass vial at room temperature.

Char, HA, and peat were added into three soils, respectively, at a ratio of exact $2 \%$ soil $(W / W)$ and mixed thoroughly on a rotary shaker for $24 \mathrm{~h}$ for sorption experiments.

\subsection{Characteristics of char, HA, and peat}

The elemental compositions $(\mathrm{C}, \mathrm{H}, \mathrm{N})$ of char, HA, and peat were determined with a high-temperature combustion method (PE 2400 SERIES II analyzer, Pekin-Elmer, Inc., USA). Oxygen content was calculated by the mass difference. Ash content was determined by combustion of char, HA, and peat at $800^{\circ} \mathrm{C}$ for $4 \mathrm{~h}$. Surface area of char

Table 1 Characteristics of soils

\begin{tabular}{llllll}
\hline Soil & $\begin{array}{l}\text { Sand } \\
(\%)\end{array}$ & $\begin{array}{l}\text { Silt } \\
(\%)\end{array}$ & $\begin{array}{l}\text { Clay } \\
(\%)\end{array}$ & $\mathrm{pH}$ & $\begin{array}{l}\text { Organic matter } \\
(\%)\end{array}$ \\
\hline Hebei & 13.7 & 59.0 & 27.3 & 7.15 & 4.53 \\
Jiangxi & 20.3 & 47.4 & 32.3 & 5.65 & 1.53 \\
Beijing & 37.6 & 51.6 & 10.8 & 7.73 & 1.35 \\
\hline
\end{tabular}

was measured by $\mathrm{N}_{2}$-BET method (ASAP 2010 surface area analyzer, Micromeritics Instrument Corp., USA). $\mathrm{pH}$ values of char, HA, and peat were measured in $0.01 \mathrm{~mol} / \mathrm{L}$ $\mathrm{CaCl}_{2}$ solution using a sample/solution ratio of $1: 5(\mathrm{~W} / \mathrm{V})$.

Char, HA, and peat were subjected to ${ }^{13} \mathrm{C}$ NMR analysis to obtain their chemical group distribution. Solid-state ${ }^{13} \mathrm{C}$ NMR data were acquired using a cross-polarization and magic angle spinning (CPMAS) on a 300-MHz NMR spectrometer (Varian, USA). Spectra were acquired at a frequency of $75 \mathrm{MHz}$, for ${ }^{13} \mathrm{CP}$ MAS spinning rate of 13 $\mathrm{kHz}$, contact time of $2 \mathrm{~ms}, 5 \mathrm{~s}$ recycle delay. The number of scans was ranged from 5000 to 10000 per sample.

\subsection{Sorption isotherms}

A batch equilibration technique with $10.0 \mathrm{mg}$ of each organic amendment (char, HA, or peat) or $0.500 \mathrm{~g}$ soil as sorbent and $30 \mathrm{~mL}$ solution were utilized for all sorption experiments. A mixture of $0.01 \mathrm{~mol} / \mathrm{L} \mathrm{CaCl}_{2}$ and $100 \mathrm{mg} / \mathrm{L}$ $\mathrm{NaN}_{3}$ was used as background electrolyte in all sorption experiments to prevent any biological degradation of PCP. In brief, 40-mL glass tubes with Teflon-lined caps were used as batch reactors. Our preliminary tests indicated that apparent equilibrium was reached before $14 \mathrm{~d}$ for char and char amended soils, and $4 \mathrm{~d}$ for other sorbents. The initial aqueous-phase PCP concentrations $\left(C_{0}\right)$ were selected to yield a set of isotherm data for each sample that distributed evenly on a $\left(q_{\mathrm{e}}\right.$ vs. $\left.C_{\mathrm{e}}\right)$ plot to span approximately 2 orders of magnitude in aqueous-phase solute equilibrium concentrations $\left(C_{\mathrm{e}}\right)$. The amount of sample in each tube corresponded to a sample-to-solution ratio that would result in 30\%-85\% uptake of PCP. Reactors filled with sorbent and initial aqueous solution were mixed at 100 $\mathrm{r} / \mathrm{min},(20 \pm 1)^{\circ} \mathrm{C}$ for $14 \mathrm{~d}$ in the dark. The $\mathrm{pH}$ was adjusted to $4.0,6.0$ and 8.0 , respectively with $0.1 \mathrm{~mol} / \mathrm{L} \mathrm{HCl}$ or $\mathrm{NaOH}$ solution. During the shaking, the $\mathrm{pH}$ values were measured at certain intervals and readjusted if necessary. At the end of the shaking period, the $\mathrm{pH}$ of suspension was measured again. After centrifugation at $1667 \times g$ for $20 \mathrm{~min}, \mathrm{PCP}$ in the supernatant solution was determined using high performance liquid chromatography (HPLC).

Control reactors prepared similarly but no sorbent were run simultaneously to assess the loss of PCP. Results of triplicate sorption at each $C_{0}$ level showed that average solution-phase concentrations of each solute were consistently within $98 \%-102 \%$ of the respective initial concentration of the same solution, indicating that microbial degradation and volatilization during the sorption and the uptake to the glass walls were negligible. Hence, no correction was made during sorption experiments.

\subsection{Determination of pentachlorophenol}

The concentrations of PCP were determined using an Agilent 1200 series HPLC with a UV detector and a C18 reversed-phase column $(250 \times 4.6 \mathrm{~mm}, 5 \mu \mathrm{m})$. Methanol and $1 \%$ acetic acid $(95: 5, V / V)$ were used as a mobile phase at a flow rate of $1 \mathrm{~mL} / \mathrm{min}$. The UV wavelength for detection of PCP was set at $220 \mathrm{~nm}$. Under such HPLC conditions, PCP showed a single peak with a retention time of $5.2 \mathrm{~min}$. The relative standard deviation (RSD) of 
triplicate determinations were less than $4.8 \%$.

\subsection{Data analysis}

The data reported are averages for triplicate measurement. The amounts of PCP adsorbed were determined by mass differences between the initial and final equilibrium concentrations. The experimental data were fitted by Freundlich model (Eq. (1)):

$q_{\mathrm{e}}=K_{\mathrm{F}} C_{\mathrm{e}}^{N}$

where, $q_{\mathrm{e}}(\mathrm{mg} / \mathrm{kg})$ is the PCP sorbed concentration on sorbents, $C_{\mathrm{e}}(\mathrm{mg} / \mathrm{L})$ is the equilibrium concentration of PCP in the aqueous phase, $K_{\mathrm{F}}\left((\mathrm{mg} / \mathrm{kg}) /(\mathrm{mg} / \mathrm{L})^{N}\right)$ is the affinity coefficient and $N$ is an exponential coefficient. The higher the $K_{\mathrm{F}}$, the higher the sorption capacity of a sorbent; while the lower the $N$ value, the more nonlinear is an isotherm. Both $K_{\mathrm{F}}$ and $N$ were determined by regression of the experimental data.

The concentration dependent sorption coefficient $\left(K_{\mathrm{d}}\right)$ was calculated based on the following Eq. (2).

$K_{\mathrm{d}}=K_{\mathrm{F}} C_{\mathrm{e}}^{N-1}$

where, $K_{\mathrm{d}}$ is the concentration rate of the sorbed PCP on the solid phase to that on the aqueous phase.

The concentration dependent organic carbonnormalized sorption coefficient $K_{\mathrm{OC}}(\mathrm{L} / \mathrm{kg}$ OC) was calculated based on the following Eq. (3).

$K_{\mathrm{OC}}=K_{\mathrm{FOC}} C_{\mathrm{e}}^{N-1}$

where, the organic carbon-normalized sorption coefficient $\left(K_{\mathrm{FOC}}\right)$ was calculated by dividing $K_{\mathrm{F}}$ by the respective fraction of organic carbon $\left(F_{\mathrm{OC}}\right)$. The values of $K_{\mathrm{OC}}$ can be used to denote directly the sorption characteristics of sorbents.

Statistical analyses were conducted with the software origin 7.5 for Windows (OriginLab Corporation, USA). Parameter sets for Eq. (1) were optimized by nonlinear regression at $95 \%$ confidence. The values including soil $\mathrm{pH}$, total concentrations of PCP in aqueous solutions, organic amendments, soils and organic amended soils are reported as mean \pm standard error.

\section{Results and discussion}

2.1 Elemental compositions, ash contents and $\mathrm{pH}$ values of char, HA, and peat

Elemental compositions of three organic amendments and surface area of char are shown in Table 2. Ash contents were lower than $10 \%$ for all amendments. The $\mathrm{H} / \mathrm{C}$ ratios followed the order: char < HA < peat. A higher $\mathrm{H} / \mathrm{C}$ ratio may suggest a higher degree of aliphaticity. The polarity $(\mathrm{N}+\mathrm{O}) / \mathrm{C}$ was found to be the highest for peat and the lowest for char. A lower $(\mathrm{N}+\mathrm{O}) / \mathrm{C}$ ratio suggests a lower polar-group content in char, reflecting a higher hydrophobicity. The $\mathrm{pH}$ order was: $\mathrm{HA}<$ peat $<$ char.

\section{$2.2{ }^{13} \mathrm{C}$ NMR spectra of organic amendments}

The ${ }^{13} \mathrm{C}$ CPMAS NMR spectra and integration results of char, HA, and peat are shown in Fig. 1 and Table 3. The spectra can be quantified by integrating the regions as follows: alkyl-C (0-50 ppm), O-alkyl-C (predominantly carbohydrates, 50-110 ppm), aromatic-C (110-160 ppm), carboxylic- and amide-C (160-190 ppm), and ketonic/aldehyde-C (190-220 ppm). The percentage of polar organic carbon (POC) was calculated as the combined fractions of 50-110 and 140-220 ppm regions of NMR spectra (Wen et al., 2007).

As shown in Table 3, the differences exist among carbon-type distributions in these amendments. Peat had the highest O-alkyl carbon content (50-110 ppm), while char had the highest aromatic carbon content (110-165 ppm). Overall, the aliphatic carbon contents increased in the order: char $<\mathrm{HA}<$ peat, consisting with the increase in $\mathrm{H} / \mathrm{C}$ ratio. $\mathrm{POC}$ were in the order: peat $>\mathrm{HA}>$ char, which is in line with the results of elemental composition (Table 2).

\subsection{Effect of $\mathrm{pH}$ on the sorption of PCP onto char, HA, and peat}

Although the solution $\mathrm{pH}$ values were adjusted in the beginning of experiments and readjusted during sorption, final $\mathrm{pH}$ values were affected by the $\mathrm{pH}$ of organic

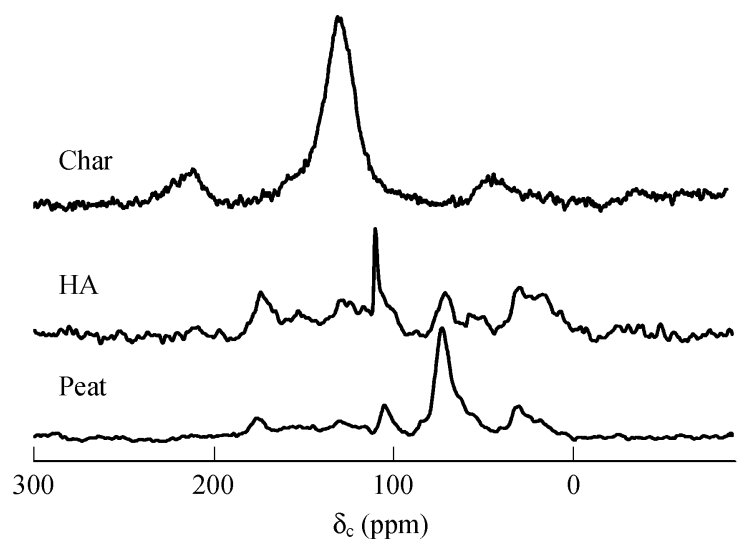

Fig. 1 CPMAS ${ }^{13} \mathrm{C}$ NMR spectra of organic amendments.

Table 2 Elemental compositions, atomic ratios, ash contents, $\mathrm{pH}$, and surface area of char, HA, and peat

\begin{tabular}{|c|c|c|c|c|c|c|c|c|c|}
\hline \multirow[t]{2}{*}{ Sample } & \multicolumn{3}{|c|}{ Elemental composition (wt.\%) } & \multicolumn{3}{|c|}{ Atomic ratio } & \multirow[t]{2}{*}{ Ash (wt.\%) } & \multirow[t]{2}{*}{$\mathrm{pH}$} & \multirow[t]{2}{*}{$\mathrm{SA}\left(\mathrm{m}^{2} / \mathrm{g}\right)$} \\
\hline & $\mathrm{C}$ & $\mathrm{H}$ & $\mathrm{N}$ & $\mathrm{H} / \mathrm{C}$ & $\mathrm{O} / \mathrm{C}$ & $(\mathrm{N}+\mathrm{O}) / \mathrm{C}$ & & & \\
\hline Char & 72.88 & 3.17 & 0.55 & 0.52 & 0.16 & 0.17 & 7.96 & 7.53 & 292.3 \\
\hline HA & 51.13 & 5.62 & 2.39 & 1.32 & 0.59 & 0.63 & 0.92 & 2.87 & 0.78 \\
\hline Peat & 45.32 & 6.05 & 1.05 & 1.6 & 0.73 & 0.75 & 3.53 & 4.23 & ND \\
\hline
\end{tabular}

$\mathrm{H} / \mathrm{C}$ : atomic ratio of hydrogen to carbon; $\mathrm{O} / \mathrm{C}$ : atomic ratio of oxygen to carbon; $(\mathrm{N}+\mathrm{O}) / \mathrm{C}$ : atomic ratio of sum of nitrogen and oxygen to carbon. $\mathrm{SA}$ : surface area, determined by $\mathrm{N}_{2}$-BET method. ND: not determined. 
Table 3 Integration results of solid-state ${ }^{13} \mathrm{C}$ NMR spectra and ratios of the sum of aliphatic to aromatic peak of char, HA, or peat

\begin{tabular}{|c|c|c|c|c|c|c|c|c|}
\hline & \multicolumn{6}{|c|}{ Distribution of $\mathrm{C}$ chemical shift (\%) } & \multirow[t]{2}{*}{ Aliphaticity } & \multirow[t]{2}{*}{$\mathrm{POC}(\%)$} \\
\hline & $\begin{array}{l}\text { Alkyl-C } \\
(0-50 \mathrm{ppm})\end{array}$ & $\begin{array}{l}\text { O-alkyl-C } \\
(50-110 \text { ppm })\end{array}$ & $\begin{array}{l}\text { Aromatic-C } \\
(110-140 \mathrm{ppm})\end{array}$ & $\begin{array}{l}\text { O-aryl-C } \\
(140-165 \mathrm{ppm})\end{array}$ & $\begin{array}{l}\text { Carboxyl-C } \\
(165-190 \mathrm{ppm})\end{array}$ & $\begin{array}{l}\text { Carbonyl-C } \\
(190-220 \mathrm{ppm})\end{array}$ & & \\
\hline Char & 10.4 & 7.95 & 57.5 & 13.2 & 2.56 & 8.39 & 0.259 & 32.1 \\
\hline $\mathrm{HA}$ & 27.1 & 27.1 & 19.4 & 11.4 & 10.1 & 4.9 & 1.76 & 53.5 \\
\hline Peat & 18.5 & 45.9 & 12.4 & 9.12 & 8.83 & 5.3 & 2.99 & 69.1 \\
\hline
\end{tabular}

Aliphaticity = aliphatic-C $(0-110 \mathrm{ppm}) /$ aromatic-C $(110-165 \mathrm{ppm})$. POC: percentage of polar organic carbon, was calculated from the peak areas listed above with an equation as $\mathrm{POC}=(\mathrm{O}$-alkyl-C $+\mathrm{O}$-aryl- $\mathrm{C}+$ carboxyl-C + carbonyl-C $) /($ alkyl-C $+\mathrm{O}-$ alkyl- $\mathrm{C}+$ aromatic- $\mathrm{C}+\mathrm{O}$-aryl-C + carboxyl-C + carbonyl-C) $\times 100 \%$.

amendments. Sorption of PCP onto HA at pH 8 was not applicable because it led to substantial redissolution of HA $(>40 \%)$.

PCP sorption isotherms for the char, HA, and peat under initial $\mathrm{pH} \mathrm{4,} \mathrm{6,} \mathrm{and} 8$ fit Freundlich model well (Fig. 2), with all the correlation coefficients higher than 0.99 . The resulting model parameters, along with their standard errors, and the calculated in $K_{\mathrm{OC}}$ values at $C_{\mathrm{e}}$ of 0.2 and $2.0 \mathrm{mg} / \mathrm{L}$ are presented in Table $4 . K_{\mathrm{F}}$ ranged from 5710 to 79948,3114 to 7164 , and 507 to 4346 for char, HA, and peat, respectively. Concentration-dependent organic carbon-normalized sorption coefficients $K_{\mathrm{OC}}$ at $C_{\mathrm{e}}=0.2$ and $2.0 \mathrm{mg} / \mathrm{L}$ were employed to compare the sorption capacity because the units of $K_{\mathrm{FOC}}$ were different as a result of nonlinearity. The $K_{\mathrm{OC}}$ values of char were the highest among the amendments studied. The $K_{\mathrm{OC}}$ of all amendments decreased with increasing initial $\mathrm{pH}$.

PCP is a hydrophobic weak organic acid $\left(\mathrm{p} K_{\mathrm{a}}=4.75\right)$ and exists as either a neutral or an ionized species. The neutral species represents more than $99 \%$ of all PCP when the solution $\mathrm{pH}$ is below 2 , whereas more than $95 \%$ of all
PCP is present as the anion when the $\mathrm{pH}$ is above 6 (DiazFlores et al., 2006). The neutral form of PCP is strongly hydrophobic with a low aqueous solubility (Stapleton et al., 1994). Shimizu et al. (1992) concluded that PCP sorption coefficients of ionized species were smaller than that of non-ionized species. Thus the species change could explain the decrease in $K_{\mathrm{OC}}$ values of PCP from $\mathrm{pH} 4$ to 6 . When $\mathrm{pH}$ increased from 6 to 8 , the surfaces of char, peat, and HA became more negative, hence more pentachlorophenolate anions were repelled from the surfaces (Moreno-Castilla, 1995; Diaz-Flores et al., 2006). In addition, HA and peat may be dissociated partially at higher $\mathrm{pH}$, resulting in the increases of dissolved organic matter contents and decreases of PCP sorption (Paaso et al., 2002).

All sorption isotherms of PCP onto sorbents were nonlinear, as evidence of $N$ values ranged from 0.26 to $0.94 . N$ value decreased with increasing initial $\mathrm{pH}$. $N$ value could be taken as an index of site energy distribution (Weber et al., 1992). Smaller $N$ values represent more heterogeneous sorption sites in nature. DiVincenzo and Sparks
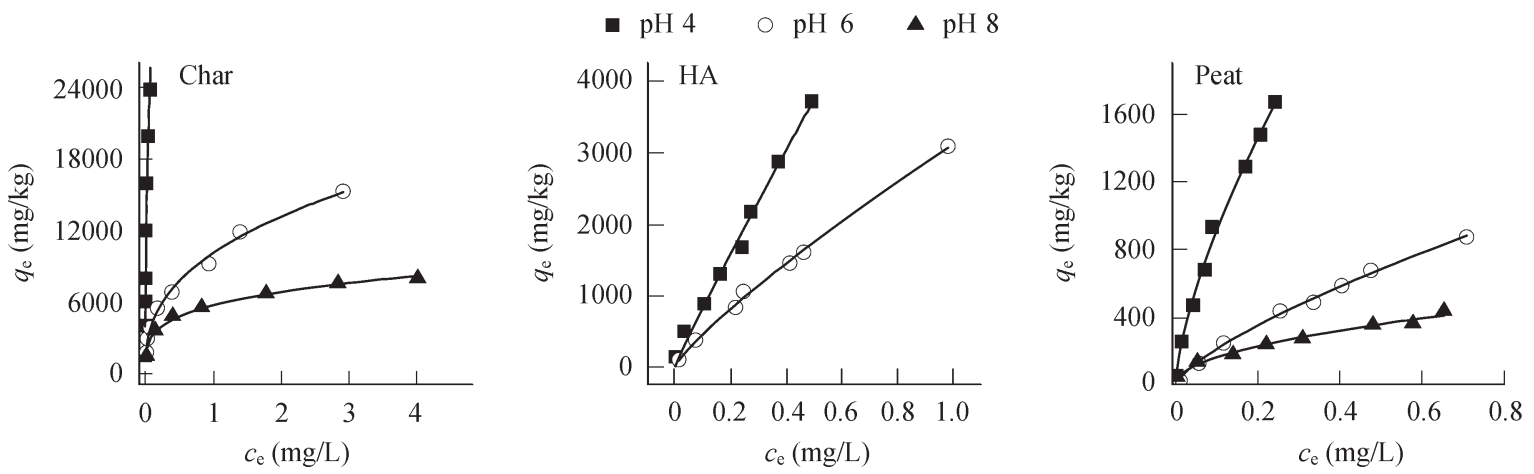

Fig. 2 Sorption isotherms of PCP onto char, HA, and peat at different initial $\mathrm{pH}$.

Table 4 Freundlich model sorption parameters and equilibrium $\mathrm{pH}$ for sorption of PCP onto char, HA, and peat

\begin{tabular}{|c|c|c|c|c|c|c|c|c|c|c|}
\hline \multirow[t]{2}{*}{ Sorbent } & \multicolumn{2}{|r|}{$\mathrm{pH}$} & \multicolumn{3}{|c|}{ Freundlich } & \multirow[t]{2}{*}{$K_{\mathrm{FOC}}$} & \multicolumn{2}{|c|}{$K_{\mathrm{d}}$} & \multicolumn{2}{|c|}{$K_{\mathrm{OC}}$} \\
\hline & Initial & Final & $R^{2}$ & $K_{\mathrm{F}}$ & $N$ & & $\begin{array}{l}C_{\mathrm{e}}= \\
0.2 \mathrm{mg} / \mathrm{L}\end{array}$ & $\begin{array}{l}C_{\mathrm{e}}= \\
2.0 \mathrm{mg} / \mathrm{L}\end{array}$ & $\begin{array}{l}C_{\mathrm{e}}= \\
0.2 \mathrm{mg} / \mathrm{L}\end{array}$ & $\begin{array}{l}C_{\mathrm{e}}= \\
2.0 \mathrm{mg} / \mathrm{L}\end{array}$ \\
\hline \multirow[t]{3}{*}{ Char } & 4.00 & $4.38 \pm 0.06$ & 0.918 & $79948 \pm 18099$ & $0.44 \pm 0.03$ & 109698 & 197951 & 54121 & 271614 & 74239 \\
\hline & 6.00 & $6.94 \pm 0.09$ & 0.994 & $10096 \pm 1689$ & $0.38 \pm 0.02$ & 13853 & 27294 & 6579 & 37451 & 9027 \\
\hline & 8.00 & $7.39 \pm 0.17$ & 0.986 & $5701 \pm 1209$ & $0.26 \pm 0.02$ & 7823 & 18791 & 3411 & 25784 & 4680 \\
\hline \multirow[t]{2}{*}{ HA } & 4.00 & $4.00 \pm 0.15$ & 0.990 & $7164 \pm 4809$ & $0.94 \pm 0.04$ & 14012 & 7903 & 6867 & 15456 & 13431 \\
\hline & $\begin{array}{l}6.00 \\
8.00\end{array}$ & $5.17 \pm 0.06$ & 0.998 & $3114 \pm 50$ & $\begin{array}{l}0.83 \pm 0.02 \\
\mathrm{NA}\end{array}$ & 6091 & 4069 & 2775 & 7957 & 5428 \\
\hline \multirow[t]{3}{*}{ Peat } & 4.00 & $4.13 \pm 0.05$ & 0.994 & $4346 \pm 265$ & $0.68 \pm 0.03$ & 9590 & 7303 & 3476 & 16114 & 7670 \\
\hline & 6.00 & $5.94 \pm 0.07$ & 0.997 & $1132 \pm 26$ & $0.72 \pm 0.02$ & 2498 & 1764 & 935 & 3894 & 2063 \\
\hline & 8.00 & $6.26 \pm 0.13$ & 0.983 & $507 \pm 21$ & $0.49 \pm 0.04$ & 1119 & 1150 & 357 & 2537 & 787 \\
\hline
\end{tabular}

NA: not applicable. 
(2001) suggested that neutral form of PCP partitioned by hydrophobically binding to the soil with linear sorption isotherm, while the charged form sorbed by a more specific exothermic adsorption reaction with $N$ value lower than 1 . Char is a kind of high-surface-area carbonaceous material (HSACM) that has showed high sorption capacity and sorption isotherm nonlinearity for HOCs (Cornelissen et al., 2005). The sorption of HOCs to chars is dominated by adsorptive pore-filling processes (Nguyen et al., 2007). Several authors (Jung et al., 2001; El-Sheikh et al., 2004; Diaz-Flores et al., 2006) have reported that $\pi-\pi$ interactions control the adsorption of both neutral and anion forms of phenol and chlorophenols on granular activated carbon. This could explain the highest $K_{\mathrm{OC}}$ values and the lowest $N$ values of char.

Chiou et al. (2000) compared the sorption of neutral dichlorophenol (DCP) on peat and HA extracted from peat. Both sorption isotherms showed distinct nonlinearity. They deemed that additional specific interactions with the active groups of sorbents are responsible for the obviously nonlinear sorption of polar solutes. However, Moreno-Castilla (2004) suggested that phenol and water can compete to form $\mathrm{H}$-bonds with surface active groups, such as carboxyl groups. In this competition water molecules are preferentially bound by $\mathrm{H}$-bonds. Accordingly, the direct interactions between PCP and active groups of sorbents would be ignored. Wen et al. (2007) found that HOC sorption nonlinearity index $N$ value was negatively correlated with the polarity of sorbents, suggesting the importance of polarity in the sorption isotherm nonlinearity. The polarity of peat was higher than that of HA (Tables 2 and 3), which was assumed to result in the relatively low $N$ value of peat.

\subsection{Sorption of PCP on unamended and char, HA, and peat amended soils}

Figure 3 shows the PCP sorption isotherms from water by unamended and organic amended soils. All the sorption isotherms fit the Freundlich model well, with the correlation coefficients higher than 0.99 (Table 5). Effects of char, $\mathrm{HA}$, and peat on sorption $\mathrm{pH}$ were measured because sorption of PCP was affected by $\mathrm{pH}$. Amendment with HA lowered soil solution $\mathrm{pH}$ by $0.14,0.26$, and 0.24 units for Hebei, Jiangxi, and Beijing soils, respectively, while amendment with char increased solution $\mathrm{pH}$ by 0.35 and 0.62 units for Hebei and Jiangxi soils, respectively. No significant change of sorption $\mathrm{pH}$ was detected for all soils amended with peat and Beijing soil amended with char. Overall, the sorption $\mathrm{pH}$ was in the range of 5.36-7.63, and PCP was present as anionic form predominantly.

For unamended soils, the $K_{\mathrm{d}}$ values followed the order Hebei > Jiangxi $>$ Beijing. The $N$ values were Jiangxi $>$ Beijing $\geqslant$ Hebei. Fingler et al. (2004) found that the sorption of predominantly ionized chlorophenols increased linearly with increasing sorbent organic-matter content and decreased with increasing sorbent $\mathrm{pH}$. Accordingly, the highest organic matter content of Hebei soil was responsible for the highest $K_{\mathrm{d}}$ value; the lowest organic matter content and the highest soil solution $\mathrm{pH}$ value resulted in the lowest $K_{\mathrm{d}}$ value of Beijing soil.

Amendment with char, HA, and peat significantly
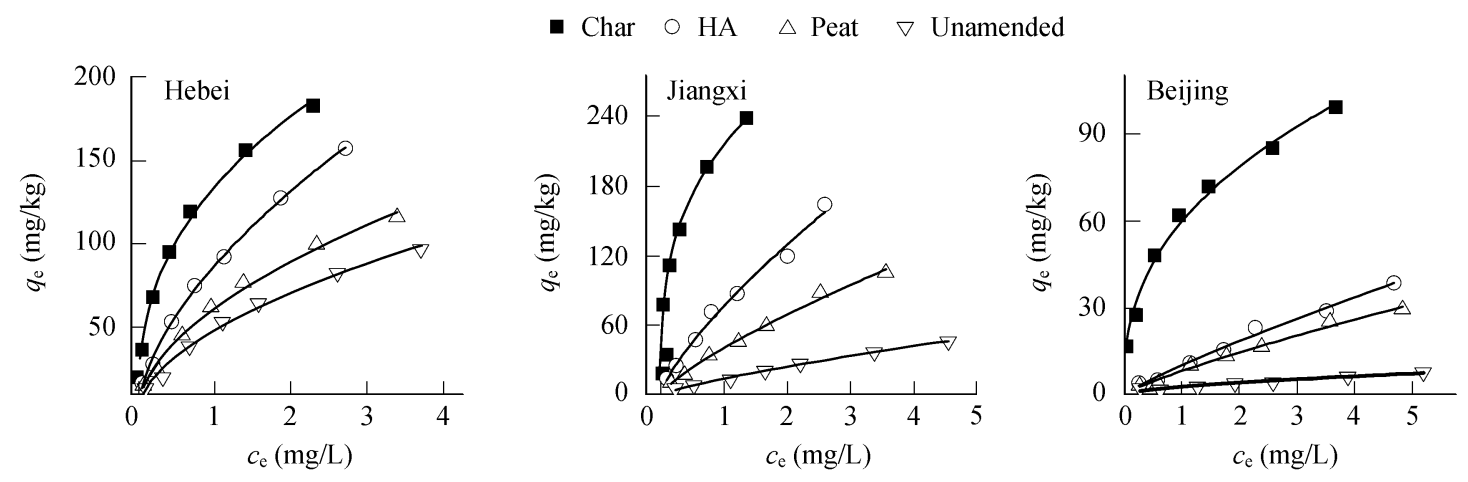

Fig. 3 Sorption isotherms of PCP onto three soils amended and unamended with organic amendments. The symbols denote experimental data points, and the lines are the Freundlich model fittings.

Table 5 Freundlich model sorption parameters and equilibrium $\mathrm{pH}$ for sorption of PCP on unamended and amended soils

\begin{tabular}{|c|c|c|c|c|c|c|c|c|}
\hline & \multirow[t]{2}{*}{ Soil } & \multirow[t]{2}{*}{$F_{\text {OC }}(\%)$} & \multirow[t]{2}{*}{ Equilibrium $\mathrm{pH}$} & \multicolumn{3}{|c|}{ Freundlich } & \multicolumn{2}{|c|}{$K_{\mathrm{d}}$} \\
\hline & & & & $R^{2}$ & $K_{\mathrm{F}}$ & $N$ & $C_{\mathrm{e}}=0.2 \mathrm{mg} / \mathrm{L}$ & $C_{\mathrm{e}}=2.0 \mathrm{mg} / \mathrm{L}$ \\
\hline \multirow[t]{4}{*}{ Hebei } & Char-amended & 4.04 & $7.36 \pm 0.06$ & 0.984 & $132.0 \pm 3.8$ & $0.43 \pm 0.03$ & 330 & 88.9 \\
\hline & HA-amended & 3.60 & $6.87 \pm 0.02$ & 0.998 & $87.0 \pm 1.2$ & $0.60 \pm 0.02$ & 166 & 65.9 \\
\hline & Peat-amended & 3.48 & $7.18 \pm 0.10$ & 0.990 & $61.6 \pm 1.8$ & $0.54 \pm 0.03$ & 129 & 44.8 \\
\hline & Unamended & 2.63 & $7.01 \pm 0.08$ & 0.992 & $48.6 \pm 1.5$ & $0.55 \pm 0.03$ & 100 & 35.6 \\
\hline \multirow[t]{4}{*}{ Jiangxi } & Char-amended & 2.33 & $6.24 \pm 0.12$ & 0.988 & $217 \pm 18$ & $0.43 \pm 0.08$ & 543 & 147 \\
\hline & HA-amended & 1.90 & $5.36 \pm 0.03$ & 0.988 & $77.0 \pm 3.1$ & $0.75 \pm 0.05$ & 115 & 64.8 \\
\hline & Peat-amended & 1.78 & $5.71 \pm 0.09$ & 0.994 & $40.7 \pm 1.5$ & $0.77 \pm 0.04$ & 58.9 & 34.7 \\
\hline & Unamended & 0.89 & $5.62 \pm 0.05$ & 0.996 & $14.3 \pm 0.5$ & $0.78 \pm 0.03$ & 20.4 & 12.3 \\
\hline \multirow[t]{4}{*}{ Beijing } & Char-amended & 2.22 & $7.63 \pm 0.06$ & 0.992 & $59.7 \pm 1.3$ & $0.40 \pm 0.02$ & 157 & 39.4 \\
\hline & HA-amended & 1.79 & $7.32 \pm 0.07$ & 0.989 & $10.3 \pm 0.7$ & $0.86 \pm 0.06$ & 12.9 & 9.35 \\
\hline & Peat-amended & 1.67 & $7.40 \pm 0.09$ & 0.989 & $8.31 \pm 0.57$ & $0.82 \pm 0.05$ & 11.1 & 7.34 \\
\hline & Unamended & 0.78 & $7.56 \pm 0.08$ & 0.985 & $2.91 \pm 0.31$ & $0.59 \pm 0.03$ & 5.63 & 2.19 \\
\hline
\end{tabular}


increased PCP sorption in all soils, which $K_{\mathrm{F}}$ of amended soils were 1.3 to 20.5 times as those of unamended soils. Amendment with char decreased the $N$ value obviously. No significant difference of $N$ value was found for HA and peat amendment, except that increased $N$ values were found for HA and peat amended Beijing soil. Char-amended soil possessed the greatest PCP sorption enhancement for all soils, which was ascribed to the largest sorptive ability of char at both low and high $\mathrm{pH}$. At the equilibrium concentration of $0.2 \mathrm{mg} / \mathrm{L}$, the $K_{\mathrm{d}}$ enhancement factors were 3.3, 26.6, and 27.9 for Hebei, Jiangxi, and Beijing soils, respectively. Hebei soil had the lowest enhancement factor which may be attributed to the relatively high $K_{\mathrm{d}}$ value of unamended Hebei soil. We assume that the sorptive ability of soil for PCP did not change after the addition of char, calculation showed that $2 \%$ char contributed to more than $90 \%$ of the sorption by char-amended Jiangxi and Beijing soils, and more than $60 \%$ of the sorption by char-amended Hebei soil. This indicated the predominance of char over soil in sorbing PCP. However, the sorption was not the simple sum of the respective contributions from soil and char. NOM could sorption on char, leading adsorption site competition and pore blockage (Pignatello et al., 2006). Thus, the adsorption of NOM onto char surface is assumed to reduce char adsorptivity for PCP.

Compared with unamended soils, the $K_{\mathrm{d}}$ enhancement factors of HA-amended soils were 1.7 (Hebei soil), 5.3 (Jiangxi soil), and 2.3 (Beijing soil) at the equilibrium concentration of $0.2 \mathrm{mg} / \mathrm{L}$. These enhancement factors were slightly higher than those of peat-amended soils. Again, assume that the sorptive ability of soil for PCP did not change in the presence of HA, 2\% HA contributed $39.8 \%$ (Hebei soil), $82.3 \%$ (Jiangxi soil), and $56.4 \%$ (Beijing soil) to the sorption by HA-amended soils, and $2 \%$ peat contributed $22.5 \%, 65.4 \%$, and $49.3 \%$ to the sorption by peat-amended Hebei, Jiangxi, and Beijing soils, respectively. $K_{\mathrm{d}}$ of Jiangxi soil showed the largest enhancement after HA and peat addition when compared with those of Beijing soil, which was related to the high sorption ability of peat and HA at low $\mathrm{pH}$.

\section{Conclusions}

Sorption abilities of soil organic amendments including char, HA, and peat, highly depend on $\mathrm{pH}$. The sorption intensity of PCP on organic amendments decreased with increasing sorption $\mathrm{pH}$, which not only due to the change of PCP species, but also the increase of the static repulsion between the sorbent surface and anionic PCP. The sorption intensity followed the order: char $>$ HA $>$ peat, and the nonlinearity of isotherms were: char $>$ peat $>$ HA. Addition of HA to soils decreased the $\mathrm{pH}$ of all soils, while addition of char increased the $\mathrm{pH}$ except that of Beijing soil. Soil organic amendments enhanced the sorption abilities of PCP significantly. The sorption enhancement factor followed the order: char $>$ HA $>$ peat, which was in accord with their sorption abilities. The sorption enhancement factors were soil and amendment characteristics dependent. These results provided direct evidence that addition of traditional soil amendments could enhance the sorption of PCP. This information may aid both in predicting environmental fates of hydrophobic ionizable organic compounds, and in developing remediation strategies.

\section{Acknowledgments}

This work was supported by the Knowledge Innovation Program of the Chinese Academy of Sciences (No. KZCX-1-YW-06-03) and the National Natural Science Foundation of China (No. 40730740).

\section{References}

Braida W J, Pignatello J J, Lu Y F, Ravikovitch P I, Neimark A V, Xing B S, 2003. Sorption hysteresis of benzene in wood charcoal particles. Environmental Science and Technology, 37(2): 409-417.

Chiou C T, Kile D E, Rutherford D W, Sheng G, Boyd S A, 2000. Sorption of selected organic compounds from water to a peat soil and its humic-acid and humin fractions: Potential sources of the sorption nonlinearity. Environmental Science and Technology, 34(7): 1254-1258.

Cornelissen G, Elmquist M, Groth I, Gustafsson Ö, 2004. Effect of sorbate planarity on environmental black carbon sorption. Environmental Science and Technology, 38(13): 3574-3580.

Cornelissen G, Gustafsson Ö, Bucheli T D, Jonker M T O, Koelmans A A, van Noort P C M, 2005. Extensive sorption of organic compounds to black carbon, coal, and kerogen in sediments and soils: mechanisms and consequences for distribution, bioaccumulation, and biodegradation. Environmental Science and Technology, 39(18): 6881-6895.

Davies N A, Edwards P A, Lawrence M A M, Taylor M G, Simkiss K, 1999. Influence of particle surfaces on the bioavailability to different species of 2,4-dichlorophenol and pentachlorophenol. Environmental Science and Technology, 33(14): 2465-2468.

Day P R, 1965. Particle fractionation and particle-size analysis. American Society of Agronomy: Madison WI, 545-567.

Dercova K, Sejakova Z, Skokanova M, Barancikova G, Makovnikova J, 2006. Potential use of organomineral complex (OMC) for bioremediation of pentachlorophenol (PCP) in soil. International Biodeterioration and Biodegradation, 58(3-4): 248-253.

Diaz-Flores P E, Leyva-Ramos R, Guerrero-Coronado R M, Mendoza-Barron J, 2006. Adsorption of pentachlorophenol from aqueous solution onto activated carbon fiber. Industrial and Engineering Chemistry Research, 45(1): 330-336.

DiVincenzo J P, Sparks D L, 2001. Sorption of the neutral and charged forms of pentachlorophenol on soil: evidence for different mechanisms. Archives of Environmental Contamination and Toxicology, 40(4): 445-450.

El-Sheikh A H, Newman A P, Al-Daffaee H K, Phull S S, Lynch D E, 2004. The use of activated carbons with basic properties for the treatment of 2-chlorophenol. Adsorption Science and Technology, 22(6): 451-461.

Fingler S, Drevenkar V, Fröbe Z, 2004. Sorption of chlorophenolates in soils and aquifer and marine sediments. Archives of Environmental Contamination and Toxicology, 48(1): 3239.

Ge J, Pan J, Fei Z, Wu G, Giesy J P, 2007. Concentrations 
of pentachlorophenol (PCP) in fish and shrimp in Jiangsu Province, China. Chemosphere, 69(1): 164-169.

Hatzinger P B, Alexander M, 1995. Effect of aging of chemicals in soil on their biodegradability and extractability. Environmental Science and Technology, 29(2): 537-545.

Hernández-Soriano M C, Peña A, Mingorance M D, 2007. Retention of organophosphorous insecticides on a calcareous soil modified by organic amendments and a surfactant. The Science of the Total Environment, 378(1-2): 109-113.

Jung M W, Ahn K H, Lee Y, Kim K P, Rhee J S, Tae Park J, Paeng K J, 2001. Adsorption characteristics of phenol and chlorophenols on granular activated carbons (GAC). Microchemical Journal, 70(2): 123-131.

Mbagwu J S C, Piccolo A, 1989. Changes in soil aggregate stability induced by amendment with humic substances. Soil Technology, 2(1): 49-57.

Moreno-Castilla C, 2004. Adsorption of organic molecules from aqueous solutions on carbon materials. Carbon, 42(1): 8394.

Moreno-Castilla C, Rivera-Utrilla J, Lopez-Ramon M V, carrasco-Marin F, 1995. Adsorption of some substituted phenols on activated carbons from a bituminous coal. Carbon, 33(6): 845-851.

Nelson D W, Sommers L E, 1982. Methods of soil analysis: Part 2. Total carbon, organic carbon and organic matter. Madison WI: ASA and SSSA. 539-579.

Nguyen T H, Cho H H, Poster D L, Ball W P, 2007. Evidence for a pore-filling mechanism in the adsorption of aromatic hydrocarbons to a natural wood wood char. Environmental Science and Technology, 41(4): 1212-1217.

Paaso N, Peuravuori J, Lehtonen T, Pihlaja K, 2002. Sedimentdissolved organic matter equilibrium partitioning of pentachlorophenol: the role of humic matter. Environment International, 28(3): 173-183.

Pignatello J J, Kwon S, Lu Y, 2006. Effect of natural organic substances on the surface and adsorptive properties of environmental black carbon (char): attenuation of surface activity by humic and fulvic acid. Environmental Science and Technology, 40(24): 7757-7763.

Sheng G Y, Yang Y N, Huang M S, Yang K, 2005. Influence of $\mathrm{pH}$ on pesticide sorption by soil containing wheat residuederived wood char. Environmental Pollution, 134(3): 457463.
Shimizu Y, Yamazaki S, Terashima Y, 1992. Sorption of anionic pentachlorophenol (PCP) in aquatic environments: the effect of $\mathrm{pH}$. Water Science and Technology WSTED 4, 25(11): 41-48.

Si Y B, Zhang J, Wang S Q, Zhang L A, Zhou D M, 2006. Influence of organic amendment on the adsorption and leaching of ethametsulfuron-methyl in acidic soils in China. Geoderma, 130(1-2): 66-76.

Skrbic B, Durisic-Mladenovic N, 2007. Principal component analysis for soil contamination with organochlorine compounds. Chemosphere, 68(11): 2144-2152.

Stapleton M G, Sparks D L, Dentel S K, 1994. Sorption of pentachlorphenol to HDTMA-clay as a function of ionicstrength and $\mathrm{pH}$. Environmental Science and Technology, 28(13): 2330-2335.

Tang J X, Petersen E J, Huang Q X, Weber W J, 2007. Development of engineered natural organic sorbents for environmental applications: 3. Reducing PAH mobility and bioavailability in contaminated soil and sediment systems. Environmental Science and Technology, 41(8): 2901-2907.

Tang J X, Weber W J, 2006. Development of engineered natural organic sorbents for environmental applications. 2. Sorption wood characteristics and capacities with respect to phenanthrene. Environmental Science and Technology, 40(5): 1657-1663.

Weber W J, McGinley P M, Katz L E, 1992. A distributed reactivity model for sorption by soils and sediments. 1. Conceptual basis and equilibrium assessments. Environmental Science and Technology, 26(10): 1955-1962.

Weber W J, Tang J X, Huang Q G, 2006. Development of engineered natural organic sorbents for environmental applications. 1. Materials, approaches, and wood characterizations. Environmental Science and Technology, 40(5): 1650-1656.

Wen B, Zhang J J, Zhang S Z, Shan X Q, Khan S U, Xing B S, 2007. Phenanthrene sorption to soil humic acid and different humin fractions. Environmental Science and Technology, 41(9): 3165-3171.

Zhu D Q, Kwon S, Pignatello J J, 2005. Adsorption of singlering organic compounds to wood wood charcoals prepared under different thermochemical conditions. Environmental Science and Technology, 39(11): 3990-3998. 